with fresh or deep-frozen semen 24 or 36 hours after injection of 500 U.I . hCG at proestrus. After slaughtering, oocytes were collected, treated according to the classical histological techniques (10 $\mu$-sections) and observed by photon microscopy.

Results showed that the percentage of oocytes fertilized per sow and the number of spermatozoa per egg were significantly lower in sows inseminated with frozen semen than in those inseminated with fresh semen (37.2 vs $81 \%$ fertilized oocytes and 0.9 vs 36.9 spermatozoa/egg, respectively).

In contrast, histological analysis of the eggs did not show any difference between frozen and fresh semen relative to fertilization quality. Each oocyte penetrated by a frozen spermatozoon emitted the second polar globule and developed. No specific abnormality related to insemination with frozen semen was observed in the activation process.

Results showed a predominance of the pronucleus stage in all groups and the presence of segmented eggs only after insemination with fresh semen.

Whatever the previously studied parameters there was no difference between animals inseminated at different times after hCG.

\title{
Effect of freezing on the nucleus of boar spermatozoa
}

\author{
S. HAMAMAH ${ }^{(1)}$, M. PAQUIGNON ${ }^{(2)}$, J.C. NICOLLE $^{(1)}$
}

(1) INRA, Station de Physiologie de la Reproduction, Nouzilly, 37380 Monnaie.

(2) Institut Technique du Porc, M.N.E., 149, rue de Bercy, 75595 Paris Cedex XII.

A study was made with the aim of testing the effect of deep-freezing on the nucleus quality of boar spermatozoa. Two techniques of analysis were used : staining sperm with acridine orange to study DNA denaturation and cytophotometric measurement of chromatin after staining DNA by Feulgen method.

Results showed that after staining with acridine orange, the percentage of spermatozoa whose nucleus possessed denatured DNA did not change before and after freezing $(7.1$ vs $10.7 \%$, respectively). In contrast, freezing caused a significant reduction in DNA-Feulgen content of the nucleus (4.83 vs 4.27, respectively before and after freezing) and in its surface $\left(31.3 \mu \mathrm{m}^{2} v \mathrm{~s}\right.$ $30.5 \mu \mathrm{m}^{2}$, before and after freezing, respectively). Quantitative analysis of DNA-Feulgen showed an effect of freezing on the structure of chromatin.

\section{Bacteriological characteristics of boar semen used in artificial insemination}

\section{F. MADEC}

Ministère de l'Agriculture, Direction de la Qualité, Station de Pathologie Porcine, B.P. 9, 22440 Ploufragan

Two trials were conducted in order to assess the bacterial contamination of extended semen under practical farm conditions. A preliminary trial involving 20 semen samples prepared for artificial insemination showed that semen microflora remained quite steady during the first 24 hours of storage at $18-20^{\circ} \mathrm{C}$. However, after 48 hours of storage at $20^{\circ} \mathrm{C}$ a significant increase in contamination was observed. A second trial involving 60 ejaculates from 22 boars (4 herds) confirmed the previous findings : extented semen routinely prepared on-farm (without addition of antibiotics) may be severely contaminated and figures as high as $10^{5}$ bacteria per $\mathrm{ml}$ of extended semen were found in $8 \%$ of the samples. After 48 hours of storage the number of contaminated 
samples reached almost $50 \%$. Isolated bacteria were mainly of faecal origin. The role of hygiene at semen collection is emphasized. As semen contamination may reduce fertility, periodical bacteriological examinations of semen are recommended.

\title{
Epididymal maturation of spermatozoa : effect on gamete quality
}

\author{
J.L. DACHEUX ${ }^{(1) *}$, M. PAQUIGNON ${ }^{(2)}$ \\ (1) C.N.R.S., Laboratoire de Physiologie Comparée, Faculté des Sciences, 37200 Tours. \\ (2) I.T.P.-M.N.E., 149, rue de Bercy, 75595 Paris Cedex 12. \\ * INRA, Station de Physiologie de la Reproduction, Monnaie, 37380 Monnaie.
}

The fertilizing capacity of spermatozoa develop during their transit through the epididymis. This organ possesses several functions located in well determined sites. Epididymal cells produce and secrete in the lumen of the tubule several compounds such as numerous specific proteins. They also concentrate substances such as carnitine. The role of this compound is still unknown but the increase in carnitine and acetylcarnitine concentration in spermatozoa is associated with an enhanced motility. This epithelium constitutes a barrier between blood circulation and the luminal content of the tubule so that spermatozoa bath in a fluid exhibiting a very specific composition. Spermatozoon maturation through epididymis is characterized by successive morphological and physiological changes affecting gametes in very precise regions of epididymis. Initiation of motility is related to the increase in the movement of flagellum during transit. The biochemical analysis of proteins from the surface of the spermatozoon membrane shows three major stages in gamete maturation : loss or masking effect of protein compounds on the surface of testicular spermatozoa and occurrence of transitory then definitive compounds characteristic of a fertilizing spermatozoon. The development of the epididymal function at puberty takes place progressively. Marked disorders in epididymal activity immediately lead to a reduced fertility of the animal. Small variations in the activity of this organ might probably cause differences in gamete quality between animals especially in their preservation capacity in the liquid or in the frozen state.

\section{Patterns of circulating LH, FSH, prolactin and $E_{2} 17 \beta$ in the gilt during the follicular phase of the oestrus cycle}

\author{
Armelle PRUNIER ${ }^{(1)}$, Sylvaine CAMOUS ${ }^{(2)}$, J.P. RAVAULT ${ }^{(3)}$, \\ Françoise MARTINAT-BOTTE ${ }^{(4)}$
}

(1) INRA, Station de Recherches Porcines, Saint-Gilles, 35590 L'Hermitage.

(2) INRA, Station de Physiologie animale, 78350 Jouy-en-Josas.

(3) INRA, Station de Physiologie de la Reproduction, Nouzilly, 37380 Monnaie.

(4) I.T.P.-M.N.E., 149, rue de Bercy, 75595 Paris Cedex 12.

Blood samples were taken from 5 cyclic gilts every 15 minutes for 108 hours between days 15 and 18 of the oestrus cycle. Plasma concentrations of LH (luteinizing hormone), FSH (follicle stimulating hormone) and PRL (prolactin) were measured in the jugular vein and those of $E_{2} 17 \beta$ (oestradiaol-17 $\beta$ ) in the utero-ovarian vein.

In the late follicular/early luteal phase (days 15 and 16), LH pulses were numerous and their frequency close to 1 per hour. This high secretion could be necessary to the preovulatory growth of follicles. PRL secretion was also high.

Thereafter, the basal level, frequency and amplitude of LH pulses decreased and remained low at least between -36 and -12 hours before the preovulatory LH surge. PRL and FSH concentrations also declined while those of $E_{2} 17 \beta$ increased considerably. This increase in $E_{2} 17 \beta$ levels probably induced the decline in the secretions of LH, FSH and PRL. 